\title{
Docosahexaenoic Acid Utilization During Rod Photoreceptor Cell Renewal
}

\author{
William C. Gordon ${ }^{1}$ and Nicolas G. Bazan ${ }^{1,2}$ \\ Louisiana State University 'Eye Center and ${ }^{2}$ Neuroscience Center, Now Orlcans, Louisiana 70112
}

The supply of docosahexaenoic acid (22:6) to the frog retina, and its subsequent use by retinal cells, was studied by autoradiography and biochemical methods. Different delivery routes of ${ }^{3} \mathrm{H}-22: 6$ were evaluated. Predominant uptake by the neural retina, mainly in ganglion cell axons, outer synaptic layer, and Müller cells, was observed when the radiolabeled fatty acid was given intravitreally or by short-term incubations of eyecups. In short-term eyecup incubations, Müller cells preferentially labeled, suggesting their involvement as a transient storage site. After intravenous or dorsal lymph sac injections of ${ }^{3} \mathrm{H}-22: 6$, most of the retinal label was seen in rod photoreceptor cells. Two different labeling patterns were found in rod outer segments (ROS) as a function of postinjection time: an overall diffuse labeling pattern, as well as a dense-label region at the ROS base. This dense-label region expanded until it reached the apex of the ROS after about $30 \mathrm{~d}$. HPLC analysis of fatty acid methyl esters from retinal lipid extracts showed that ${ }^{3} \mathrm{H}-22: 6$ comprised essentially all of the label until after day 46, indicating lack of metabolic recycling of this molecule. Lipid-extracted retinal residue was devoid of radioactivity, demonstrating that protein did not contain significant covalently bound label. ${ }^{3} \mathrm{H}-$ 22:6 acylated to phospholipids in photoreceptor membranes moved apically, as evidenced by the expanding labeled region from the base of the ROS. Oil droplets in both the pigment epithelium and the cone photoreceptors labeled heavily, suggesting that 22:6 may be transiently stored. ROS tips that were phagocytosed by the pigment epithelium contained label similar in density to that of the outer segments, demonstrating that 22:6-phospholipids, at least in part, cycle through the pigment epithelial cells during visual cell renewal. In parallel experiments in frogs injected with ${ }^{3} \mathrm{H}$-leucine and maintained under the same experimental conditions, well-defined, narrow protein bands were observed. Since the leading edge of the ${ }^{3} \mathrm{H}$-leucine-labeled band (rhodopsin), and that of the dense-label region of ${ }^{3} \mathrm{H}-22: 6$ migrated at the same rate, reaching the rod tips at the same time, we suggest that the ${ }^{3} \mathrm{H}-22: 6$-labeled phospholipids giving this profile are a unique molecular species noncovalently associated with rhodopsin.

\footnotetext{
Received Aug. 29, 1989; revised Dec. 26, 1989; accepted Feb. 2, 1990.

This work was supported by USPHS grants EY02377 and EY04428 from the National Eye Institute, Bethesda, MD.

Correspondence should be addressed to Nicolas G. Bazan, Louisiana State University Eye Center, 2020 Gravier Street, Suite B, New Orleans, LA 70112.

Copyright (C) 1990 Society for Neuroscience $0270-6474 / 90 / 072190-13 \$ 03.00 / 0$
}

The continuous renewal of rod cell photoreceptor membranes involves the addition of disc membranes at the base of the outer segment with ongoing displacement of discs towards the apical tip. Thereafter, discs are shed and phagocytosed by the retinal pigment epithelium. Photomembrane biogenesis and shedding are tightly regulated in such a way that these 2 processes are equal, thus maintaining a constant rod outer segments (ROS) length (Young, 1967; Bok, 1985).

Using tritium-labeled amino acids, autoradiography, and biochemical techniques, it was shown that rhodopsin, an integral membrane protein of ROS, remains associated with disc membranes during renewal (Hall et al., 1969). Unlike proteins, lipids in ROS move between discs, as well as between discs and the plasma membrane. This conclusion is based on diffuse autoradiographic labeling profiles in the ROS using tritiated palmitic, stearic, and arachidonic acids, and contrasts greatly with the distinct migrating band that is formed when tritiated amino acids are used to label ROS proteins (Bibb and Young, 1974a). The use of ${ }^{3} \mathrm{H}$-glycerol to label the backbone of phospholipids produces a band at the ROS base that rapidly diffuses throughout the outer segment, giving a final image that resembles the labeling pattern of fatty acids (Bibb and Young, 1974b). Moreover, biochemical studies on the incorporation and distribution of radiolabeled glycerol, serine, and ethanolamine in ROS indicated that lipid turnover in the photoreceptor is different from that of protein (Anderson et al., 1980a-c).

Docosahexaenoic acid, although enriched in phospholipids of ROS (Fliesler and Anderson, 1983; Bazan and Reddy, 1985), has not been studied in relation to visual cell renewal. In fact, very little is understood about the cell biology and biochemistry of this fatty acid. Docosahexaenoic acid belongs to the 18:3, n-3 fatty acid family, which animals cannot synthesize. In addition to ROS, neuronal cell membranes of both retina and brain contain by far the largest concentration of 22:6 (Fliesler and Anderson, 1983; Bazan and Reddy, 1985). Although the function of this fatty acid is not clearly defined, experiments involving dietary deprivation of its precursor suggest specific roles, since there is avid retention of 22:6 even after very prolonged periods of deprivation, as well as a gradual decrease in visual acuity, and behavioral alterations (Neuringer and Connor, 1986).

This study examined the uptake and distribution of ${ }^{3} \mathrm{H}-22: 6$ in the frog retina using autoradiographic and biochemical techniques and compared them to leucine uptake in parallel experiments. Our findings suggest, unlike previous studies, that among 22:6-containing phospholipids, some molecular species become noncovalently associated with rhodopsin in the ROS and migrate during photomembrane renewal with this protein. An ab- 
stract has reported part of these observations (Gordon and Bazan, 1989).

\section{Materials and Methods}

Animals. Rana pipiens (4-8 gm, J. M. Hazen, Albert, VT) were kept at $25^{\circ} \mathrm{C}$ in transparent plastic boxes and fed crickets (Fluker's Cricket Farm, Baton Rouge, LA) once a week. Incubators were set on a $14 \mathrm{~L}: 10 \mathrm{D}$ photoregime. Animals were cycled in fluorescent light (Philips, $40 \mathrm{~W}$, cool white), which was maintained at $20 \mu \mathrm{E} / \mathrm{m}^{2} \sec$ (monitored with a LI-COR quantum/radiometer/photometer LI- $185 \mathrm{~B}$ and a quantum sensor LI-190SD measuring from 400 to $700 \mathrm{~nm}$ ), or $1.2 \times 10^{15}$ quanta/ $\mathrm{cm}^{2} \mathrm{sec}$.

${ }^{3} \mathrm{H}$-Docosahexaenoic acid and ${ }^{3} \mathrm{H}$-leucine labeling. Frogs were anesthetized by immersion in a $0.05 \%$ aqueous solution of $m$-aminobenzoic acid ethyl ester (MS-222, Sigma, St. Louis, MO) and then placed on damp cloths under a dissecting microscope. Four routes of labcling wcrc compared: intravitreal, intravenous, and dorsal lymph sac injections, as well as short-term incubations of eyecups with ${ }^{3} \mathrm{H}-22: 6$.

For intravenous injections, a slit was made through the abdominal skin, exposing a large vein just under the surface of the lateral abdominal musculature. Glass micropipettes (tip diameter, $50-100 \mu \mathrm{m}$ ) were used to inject the radiolabeled compounds. The skin was then sutured and the animals placed on their backs in finger bowls to recover. Dorsal lymph sac or intravitreal injections were made under a dissecting microscope with $10 \mu 1$ syringes fitted with $0.5 \mathrm{inch}, 32$ gauge needles (Hamilton).

${ }^{3} \mathrm{H}-22: 6\left(4,7,10,13,16,19\left[4,5-{ }^{3} \mathrm{H}(\mathrm{N})\right]\right.$; New England Nuclear, Inc.; $17.9 \mathrm{Ci} / \mathrm{mmol}, 0.69 \mathrm{mCi} / \mathrm{ml})$ was dried under $\mathrm{N}_{2}$ and resuspended in $10 \mu 1$ ethanol (the amount of radioactivity varied, as noted in each experiment, from $30-80 \mu \mathrm{Ci} / \mu \mathrm{l})$ for intravenous and dorsal lymph sac administration, or in $1 \mu \mathrm{l}$ ethanol for intravitreal injections $(30 \mu \mathrm{Ci} / \mu \mathrm{l})$.

${ }^{3} \mathrm{H}-\mathrm{leu}\left(\mathrm{L}-\mathrm{leucine}\left[4,5{ }^{-3} \mathrm{H}(\mathrm{N})\right]\right.$; American Radiolabeled Chemicals, Inc.; $60 \mathrm{Ci} / \mathrm{mmol}, 1 \mathrm{mCi} / \mathrm{ml}$ ) was dried down and resuspended in 10 $\mu \mathrm{l}$ water for intravenous and dorsal lymph sac injections, and in $1 \mu \mathrm{l}$ water for intravitreal administration. The injected ${ }^{3} \mathrm{H}$-leu activity was equivalent to the ${ }^{3} \mathrm{H}-22: 6$ activity in each experiment.

Frogs were then maintained individually in 4 inch finger bowls containing $20 \mathrm{ml}$ water in light-cycled incubators. Wash water was changed and counted daily. Figure 1 (right) illustrates the radioactivity shed daily into the holding water throughout a 19 day period for a 22:6- and for a leucine-injected frog. Totals of $180 \mu \mathrm{Ci}$ of $22: 6$ (23\% of total injected) and $480 \mu \mathrm{Ci}$ of leucine ( $69 \%$ of total injected) were found. At $1.5,2.5$, $5,7,9,19,46$, and $67 \mathrm{~d}$ after injection, frogs were killed; 25 animals were used throughout the in vivo studies. Of these, 8 died following venous delivery of the 22:6. An additional 9 animals were used for in vitro incubations and 21 animals for the leucine control experiments.

Retinal labeling by different routes of ${ }^{3} \mathrm{H}-22: 6$ administration. Labeled 22:6 was introduced intravitreally or from the systemic circulation (Fig. 2 ) and the retina examined by autoradiography. Intravitreal injection resulted in a high density of label in the neural retina. Heaviest labeling occurred in the ganglion cell axon/inner limiting membrane region, demonstrating extensive uptake by the neural retina, while the photoreceptor cells showed little or no uptake. Counting the radioactivity in the contralateral eye revealed very low labeling, showing that if any activity was released to the circulatory system, it was not taken up appreciably by the uninjected eye (Fig. $2, A, B$ ).

To label the retina by way of the systemic circulation (choriocapillaris), ${ }^{3} \mathrm{H}-22: 6$ was injected either intravenously or into the dorsal lymph sac. In both instances, most of the retinal label was found in the photoreceptor cells. Five days after injection of the radiolabeled fatty acid, the pigment epithelium and the photoreceptor cell outer segments were more heavily labeled than the neural retina, and dense label had accumulated at the base of the ROS. Fewer silver grains were observed in the inner segments, photoreceptor synaptic terminals, and nerve fiber layer (Fig. 2, $C, D$ ). Prolonged exposure times revealed ganglion cell axon/inner limiting membrane labeling as well.

Incubation of eyecups for $3 \mathrm{hr}$ in medium containing ${ }^{3} \mathrm{H}-22: 6$ resulted in massive uptake from the vitreal surface, with very high labeling around the inner limiting membrane, and minimal labeling in the ROS (Fig. 3A). Dense, radial bands were often observed to extend from the vitreous into the inner nuclear layer (Fig. $3 B$ ). These radial patterns match Müller cell profiles (Fig. 3C) described by Ramón y Cajal (1893). Within the inner nuclear layer and near these labeled processes were frequently seen small-diameter silver grain-filled spheres resem-

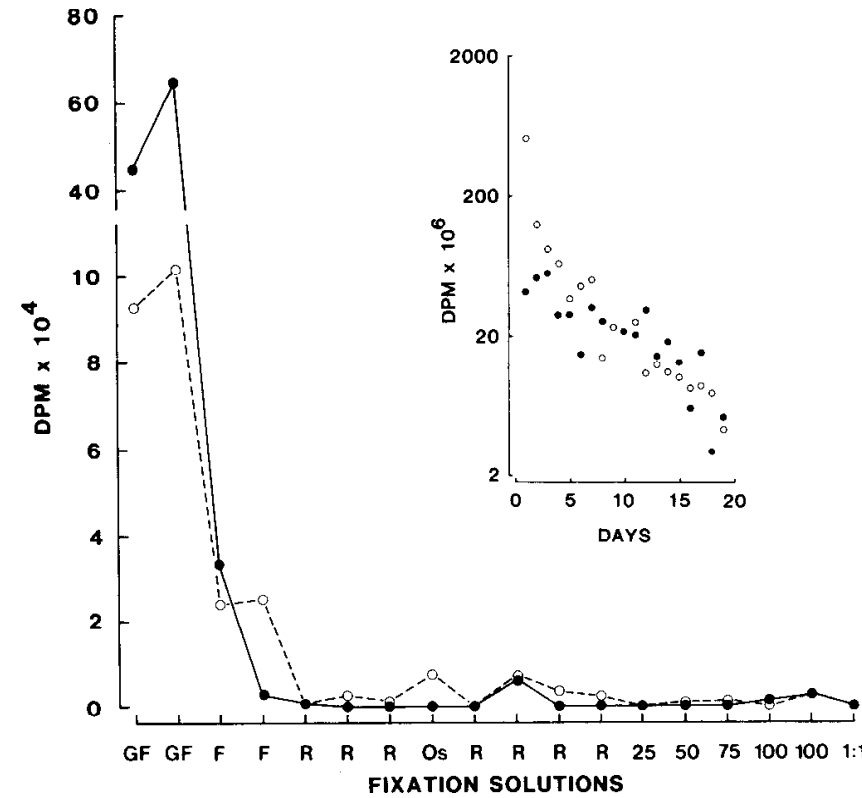

Figure 1. Radioactivity detected in retinal fixation solutions (left) and frog wash water (inset) for a typical experiment. Left, Following dorsal lymph sac injections of $500 \mu \mathrm{Ci}{ }^{3} \mathrm{H}-22: 6$ (open circles) or $500 \mu \mathrm{Ci}$ of ${ }^{3} \mathrm{H}$-leucine (filled circles) and $19 \mathrm{~d}$ of incorporation in the frog, the amount of tritium in each $5 \mathrm{ml}$ aliquot of fixation or dehydration solution was measured. Throughout fixation, $0.118 \mu \mathrm{Ci} 22: 6(0.024 \%$ of total injected) and $0.508 \mu \mathrm{Ci}$ leucine $(0.102 \%$ of total injected) were removed from each retina. Radioactivity was lost only during the primary fixation steps; counts dropped to background levels in the first buffer rinses, and remained there. $\mathrm{G} / \mathrm{F}$, glutaraldehyde/formaldehyde; $F$, formaldehyde; $R$, sodium cacodylate rinsing buffer; Os, osmium tetroxide; $25,50,75,100$, percent acetone used in a rapid dehydration series; $1: 1$, equal parts of $100 \%$ acetone and plastic. Inset, Dorsal lymph sac injections of $800 \mu \mathrm{Ci}{ }^{3} \mathrm{H}-22: 6$ or $700 \mu \mathrm{Ci}{ }^{3} \mathrm{H}$-leucine were made. Each animal was maintained in $20 \mathrm{ml}$ water in a finger bowl for $19 \mathrm{~d}$. Water was sampled and then changed once each day. A total of $180 \mu \mathrm{Ci}$ $22: 6$ (23\% of total injected) and $480 \mu \mathrm{Ci}$ leucine (69\% of total injected) was found in the wash water.

bling oil droplets. These labeled columns and spheres could be highlighted by overexposure of the autoradiograms. Prolonged autoradiographic exposures of frog retinas labeled by other routes did not often produce these Müller-like profiles or their associated "oil droplets."

After comparison of the results of the different routes of labeling, dorsal lymph sac injections were chosen to study the utilization of 22:6 during rod photoreceptor cell renewal because of the simplicity of the injection technique and the specificity of this method for the labeling of photoreceptors.

Triggering of photoreceptor shedding and phagocytosis. Animals maintained on a $24 \mathrm{hr}(14 \mathrm{~L}: 10 \mathrm{D})$ photoregime were placed for $24 \mathrm{hr}$ in constant light $\left(20 \mu \mathrm{E} / \mathrm{m}^{2} \mathrm{sec}\right)$. Then they were placed in darkness for $1 \mathrm{hr}$ (dark priming), followed by $1 \mathrm{hr}$ of light to induce shedding. Tissue was prepared as described below and phagosomes were viewed in the pigment epithelium (Gordon and Keith, 1987). The shedding response was large, with 52-91 phagosomes produced from 100 ROS. Control animals maintained in constant light did not produce phagosomes.

Tissue preparation. Animals were decapitated and pithed, and then retinas were either fixed for light microscopy and autoradiography or lipid-extracted. The left eyes were used for lipid analysis (see below). Right eyes were removed, opened by slitting the corneas, and fixed in $2 \%$ glutaraldehyde and $2 \%$ formaldehyde in $0.1 \mathrm{M}$ sodium cacodylate buffer, $\mathrm{pH} 7.3,4^{\circ} \mathrm{C}$. After $1 \mathrm{hr}$ the cornea was removed, the lens excised, and the eyecup cut into smaller pieces. Primary fixation continued overnight. Tissue was rinsed 3 times $(15 \mathrm{~min}$ each) in $0.1 \mathrm{M}$ sodium cacodylate buffer, $4^{\circ} \mathrm{C}$, postfixed for $1 \mathrm{hr}$ in $1 \% \mathrm{OsO}_{4}, 4^{\circ} \mathrm{C}$, and rinsed again. Dehydration through a stepped $20 \%$ ethanol series was followed by acetone rinses and embedding in a Polybed/Araldite plastic mixture. Throughout tissue preparation, radioactivity in the fixative buffers and 

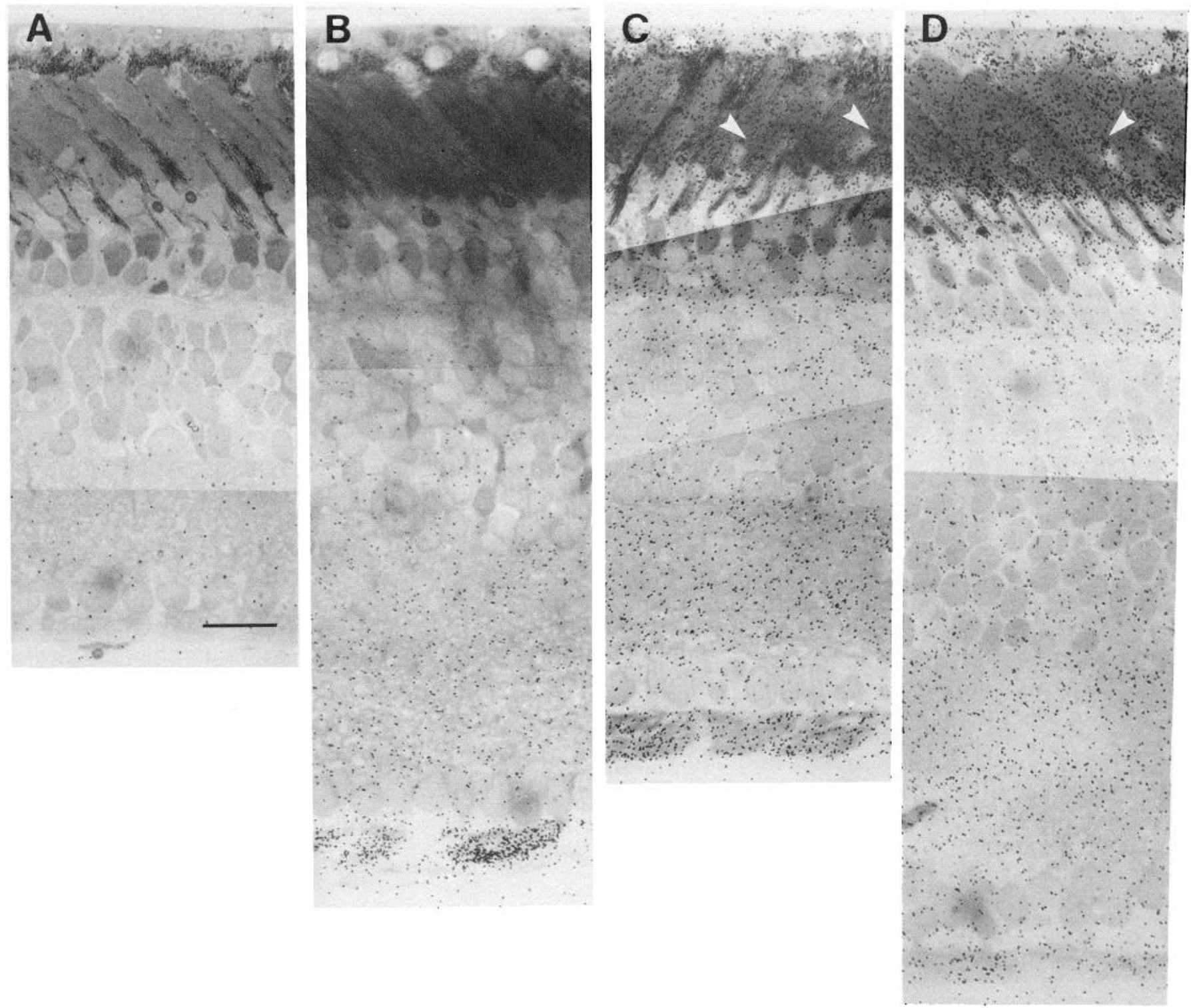

Figure 2. Comparative retinal labeling patterns using different routes of ${ }^{3} \mathrm{H}-22: 6$ administration. Autoradiograms illustrating ${ }^{3} \mathrm{H}-22: 6$ labeling in retina, $5 \mathrm{~d}$ after injection. $A$ and $B$, Contralateral and intravitreally injected eyes, respectively. $C$, Intravenously injected animal. $D$, Dorsal lymph sac-injected animal. The white arrows point to green rods. Details as in Materials and Methods. Scale bar, $20 \mu \mathrm{m}$.

dehydration solutions (maintained at $5 \mathrm{ml}$ ) was counted (Fig. 1, left). During fixation, $0.118 \mu \mathrm{Ci} 22: 6(0.024 \%$ of total injected) and 0.508 $\mu \mathrm{Ci}$ leucine $(0.102 \%$ of total injected) were lost from each retina. Only initially was tritium label released into the fixative. Following primary fixation, no tritium was lost to any of the solutions. Retinal pieces were oriented so that sections could be taken from the dorsal or ventral halves of the eye along a nasotemporal plane. After the optic nerve was removed, retinal pieces were oriented so that ROS could be viewed longitudinally. Sections from these areas (usually the ventral portions of the eye) were prepared for autoradiography.

Autoradiography. Plastic sections ( $1.5 \mu \mathrm{m}$ thick) of eyecups were placed on glass slides, dipped in NT-B2 emulsion (Kodak), and exposed for 1-5 weeks. Some sections on each slide were counterstained with toluidine blue (Polysciences, Inc., Warrington, PA) and destained in ethanol. Both stained and unstained materials were examined and photographed with a Zeiss Axioskop (Carl Zeiss, Inc., New York, NY) light microscope. Autoradiographic analysis was done in 2 ways: (1) silver grain positions were transferred manually to acetate overlays, and graphs were constructed to represent grain densities after subtraction of background (grains/unit area); (2) images of outer segments were digitized and then analyzed by computer. The second procedure was carried out as follows. Large photographs of labeled retinas were prepared, showing 15-20 outer segments. All photographs were printed at the same magnification. Individual ROS were digitized and analyzed using a Zeiss IBAS 2000 Image Analyzer. An outer segment from the photograph was aligned on the monitor and digitized. The image was then outlined and the surrounding field discarded. Autoradiographic silver grains were selected and marked by adjusting the color-intensity scale on the screen. The resulting field, containing the single ROS with its silver grains, was then fragmented into windows, within each of which a measurement was taken of the total area of the silver grains and of the cytoplasmic area represented by that portion of the ROS. The ratio of silver grain area to outer segment area was printed and the next field measured. Outer segments (8-12) were measured in this manner and plotted singly as well as averaged. The migrating fronts of the labeled molecules could be easily distinguished and measured from the resulting plots (see $\mathrm{Re}$ sults).

Lipid extraction and HPLC analysis. Liver, brain, and retina plus pigment epithelium of left eyes were extracted with chloroform: methanol $(2: 1)$ in glass-on-glass homogenizers. Lipid extracts were stored at $-40^{\circ} \mathrm{C}$ under nitrogen prior to purification (Marcheselli et al., 1988). Then, aliquots of total lipid extracts were methanolyzed with $\mathrm{BF}_{3}$-meth- 

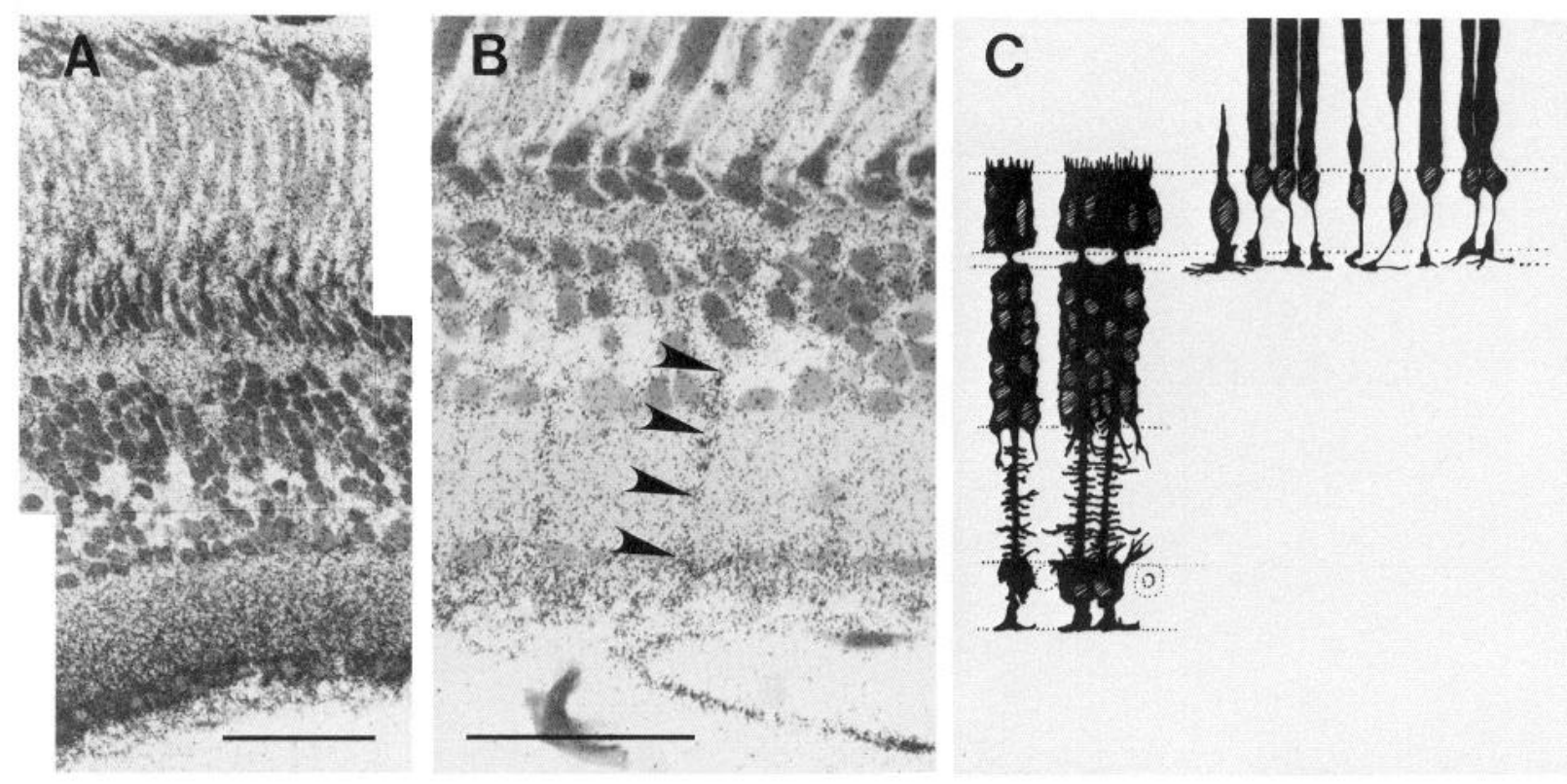

Figure 3. Eyecups incubated for $3 \mathrm{hr}$ with medium containing ${ }^{3} \mathrm{H}-22: 6$. A, Portion of eyecup showing a labeling gradient that is greatest near the vitreous and least at the rod outer segments. $B$, Overexposure of autoradiograms sometimes reveals labeled columns (arrows) that extend from the vitreous (bottom) into the inner nuclear layer. These columns resemble Müller cells in size, shape, and distribution. The large, flattened structure with heavy labeling near the base of this section is a surface blood vessel at the vitreal-retinal interface. $C$, Müller cells and photoreceptor cells are traced (from Ramón y Cajal, 1893) to scale for comparison with labeled columns in $B$. Scale bars, $50 \mu \mathrm{m}$.

anol followed by HPLC analysis (Marcheselli et al., 1988). Lipid-free tissue residues were solubilized in $1 \mathrm{~N} \mathrm{NaOH}$ and analyzed in a liquid scintillation counter.

\section{Results}

Uptake and time course of labeling of photoreceptor cells, retinal pigment epithelium, and neural retina by

\section{${ }^{3} \mathrm{H}$-22:6 or ${ }^{3} \mathrm{H}$-leucine}

Retinas labeled by these tritiated compounds were examined at $1.5,2.5,5,7,9,19$, and $46 \mathrm{~d}$ after injection. ${ }^{3} \mathrm{H}$-leucine was used as a spaciotemporal marker of the assembly of newly synthesized rhodopsin into ROS discs. Figure 4 illustrates a typical progression of leucine-labeled protein through the outer segments. Initial labeling (recorded $2 \mathrm{~d}$ postinjection) was at the base of the outer segment. Subsequent disc morphogenesis and membrane addition at the ROS base displaced the labeled band apically. Labeled disc membranes reached the ROS tip in about $30 \mathrm{~d}$, after which they were shed and phagocytosed by the pigment epithelium.

Tritiated 22:6 also initially formed a dense region at the base of the ROS, as well as diffuse labeling over the entire ROS. The densely labeled region at the base continually thickened and gradually filled the ROS, reaching the pigment epithelium in about $30 \mathrm{~d}$ (Fig. 5). The distances from the base of the ROS to the migrating fronts of the leucine band and the dense 22:6 region were measured and plotted as a function of time. Typical grain-density scans of ROS throughout the labeling periods are shown in Figure 6. Measurements from these plots show a close correlation between the displacement of the fronts of both labels (Fig. 7). ROS length bears no relationship to the frontal displacement of the band; the protein marker (leucine) and the 22:6 fatty acid comigrated, reaching the tips in $28 \mathrm{~d}$.

At $46 \mathrm{~d}$ after injection of ${ }^{3} \mathrm{H}-22: 6$ a slight decrease was apparent in silver grain density in the basal area of the ROS.
Examination of retinas at longer time periods would indicate whether this observation represented a reduction in the ${ }^{3} \mathrm{H}-22: 6$ pool that is being utilized for membrane synthesis, but this has not yet been completed.

Photoreceptor cells appeared to have the greatest affinity for 22:6 uptake, retaining label in the outer segments for the life of the disc membranes. While all plots of tritium displacement have been made from data obtained from red rods, very similar kinds of profiles were observed for green rods. Band position in green rods was also noted for both leucine (Fig. 4, 5 and 9 d) and 22:6 (Figs. $2 D$; and 5, 5 d). With both these labels, displacement distance was slightly less than that observed for red rods. Since green rods have shorter outer segments than red rods, estimates of total migration rates through the outer segment of both photoreceptor types are similar. However, not enough observations of green ROS have been made at the longer time intervals to make a conclusive statement.

Cone photoreceptors also incorporate 22:6 into their photomembranes. However, because of the small size of cone outer segments, they cannot be adequately analyzed by light microscopic autoradiography. Our current investigations at the electron microscopic level will permit resolution of this issue.

Other regions of the retina also incorporate labeled 22:6. The nerve cell fibers of the ganglion cells avidly took up 22:6, producing a dense band of silver grains at the retina/vitreous interface. Oil droplets within the photoreceptors, the pigment epithelium, and the Müller cells also labeled heavily. In the frog, red-sensitive cone cells all possess a small oil droplet, and each pigment epithelial cell has a large nucleus-size oil droplet. These all labeled heavily (Fig. 8) and only gradually lost label throughout the time course of these experiments.

When photoreceptors were induced to shed, the phagosomes in the pigment epithelial cells contained label (Fig. 8). Phagosomes produced early in the labeling experiments (Fig. $8 A, 5 \mathrm{~d}$ ) 


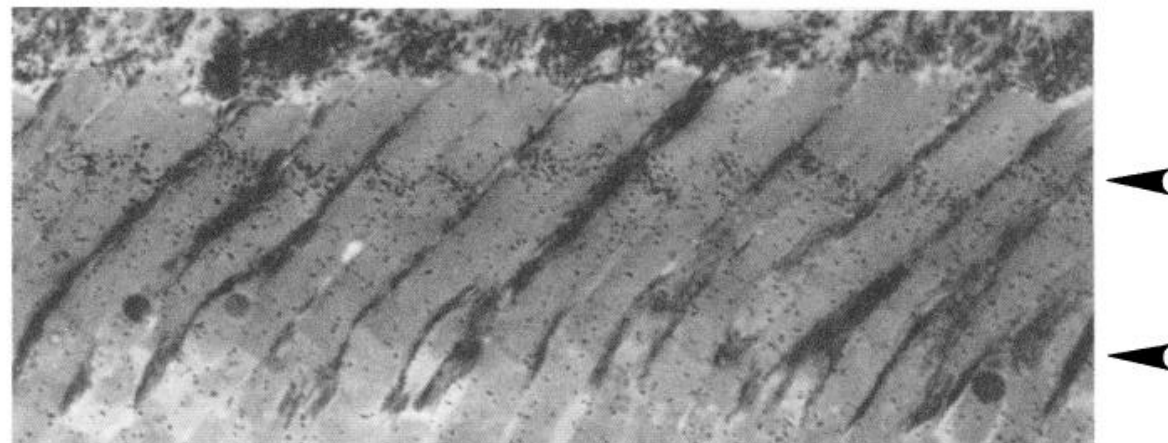

$19 d$

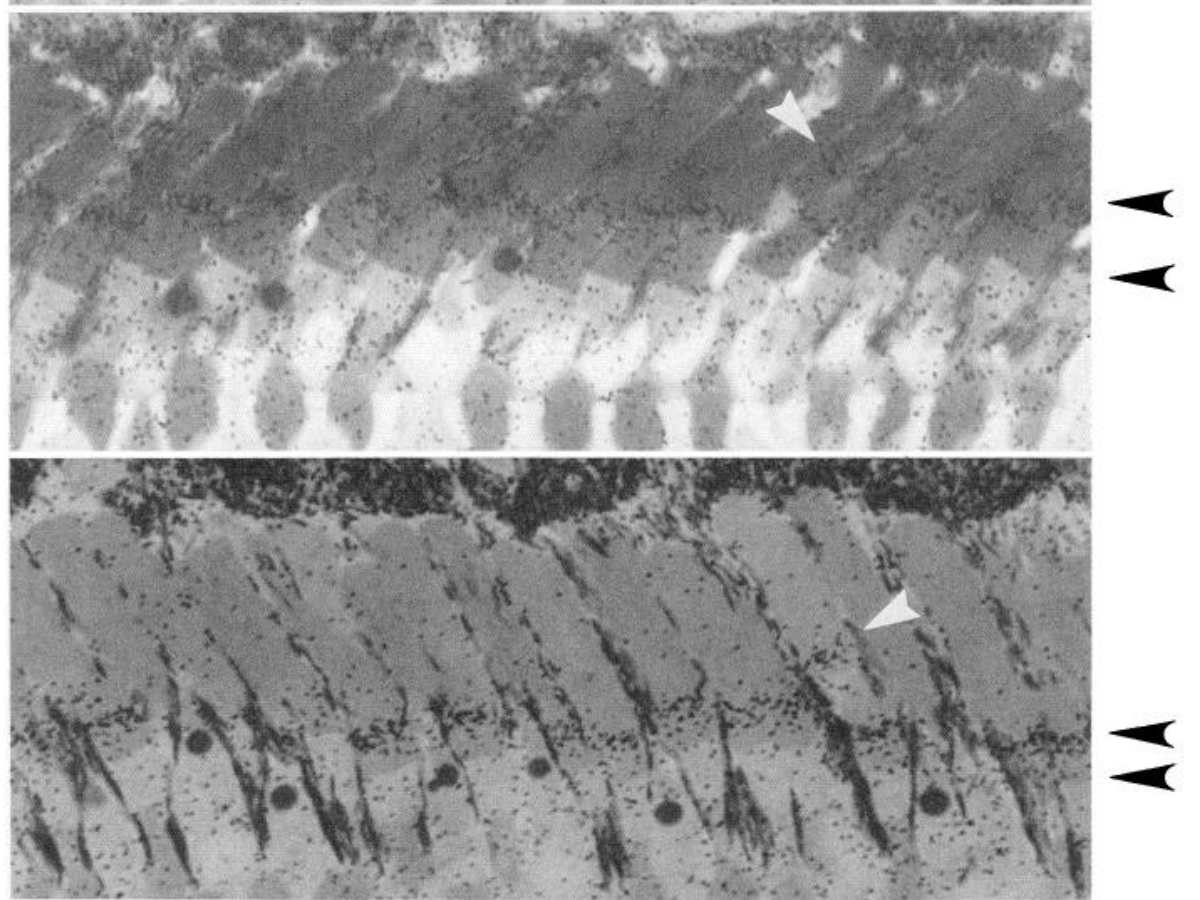

$9 d$

$5 d$

Figure 4. Labeling pattern as a function of time after injecting ${ }^{3} \mathrm{H}$-leucine. The labeling period is indicated in days to the right of each autoradiogram. Dense leucine bands mark newly synthesized protein opsin near the base of the ROS after $1.5 \mathrm{~d}$ (bottom). The distance from the ROS base to the front of the newly synthesized disc membranes (silver grain band) is indicated by pairs of black arrows at the right. White arrows indicate examples of green rods. Scale bar, $20 \mu \mathrm{m}$.

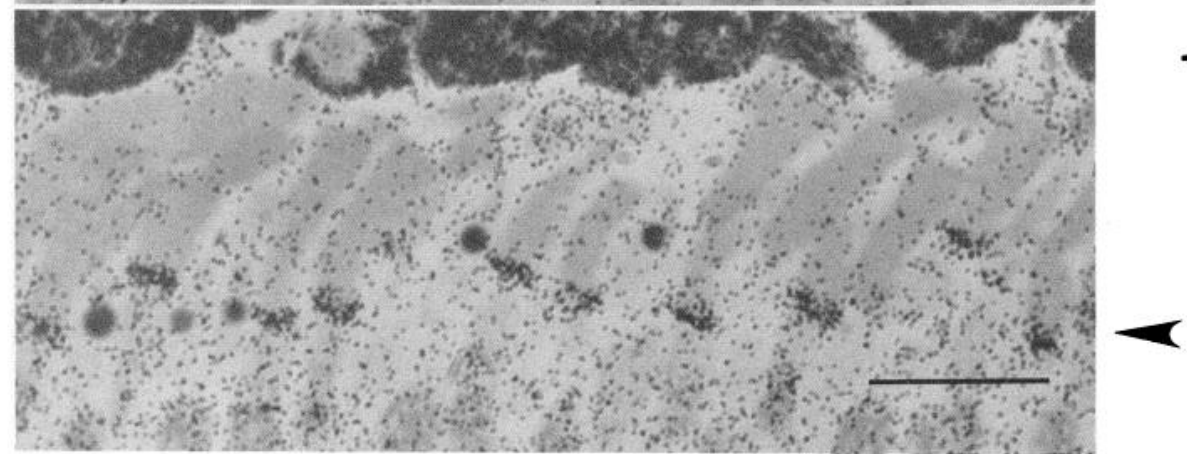

$1.5 d$

displayed diffuse ${ }^{3} \mathrm{H}-22: 6$ label, while 28 d phagosomes from densely labeled photoreceptors were heavily labeled (Fig. $8 B$ ). Leucine-injected animals, when induced to shed at day 28 , produced phagosomes with a tritium band (Fig. $8 E$ ), indicating that under our experimental conditions, discs reach the pigment epithelium in $28 \mathrm{~d}$ (Fig. 7). Interestingly, the cytoplasm of the pigment epithelium contained relatively few silver grains, even when shedding had not been induced (Fig. 8, $C, D$ ).

The amount of radioactivity within the retina was calculated from $7 \mathrm{~d}$ postinjection retinas. When $800 \mu \mathrm{Ci} 22: 6$ was injected via the lymphatic system, a total of $2.56 \mu \mathrm{Ci}(0.32 \%$ of total label) was detected in the left eye of $2.5 \mathrm{~d}$ animals, while 2.28 $\mu \mathrm{Ci}(0.23 \%$ of total label) was detected in $19 \mathrm{~d}$ animals. The right eye was prepared for light autoradiography and sections analyzed. A sample strip of retina extending from the pigment epithelium to the vitreous and 15 rod cells wide was used. The total number of silver grains was counted, normalized to $100 \%$, and the amount of label within each layer converted to a percentage. An indication of the relative labeling of 22:6 uptake at the cellular level for these 2 time points is illustrated in Table 1. These values provide an indication of the relative labeling and were obtained by assuming that the 2 eyes label in a quantitatively similar manner and that the biochemical analysis of the left eye can be used as a base for the calculations of the 


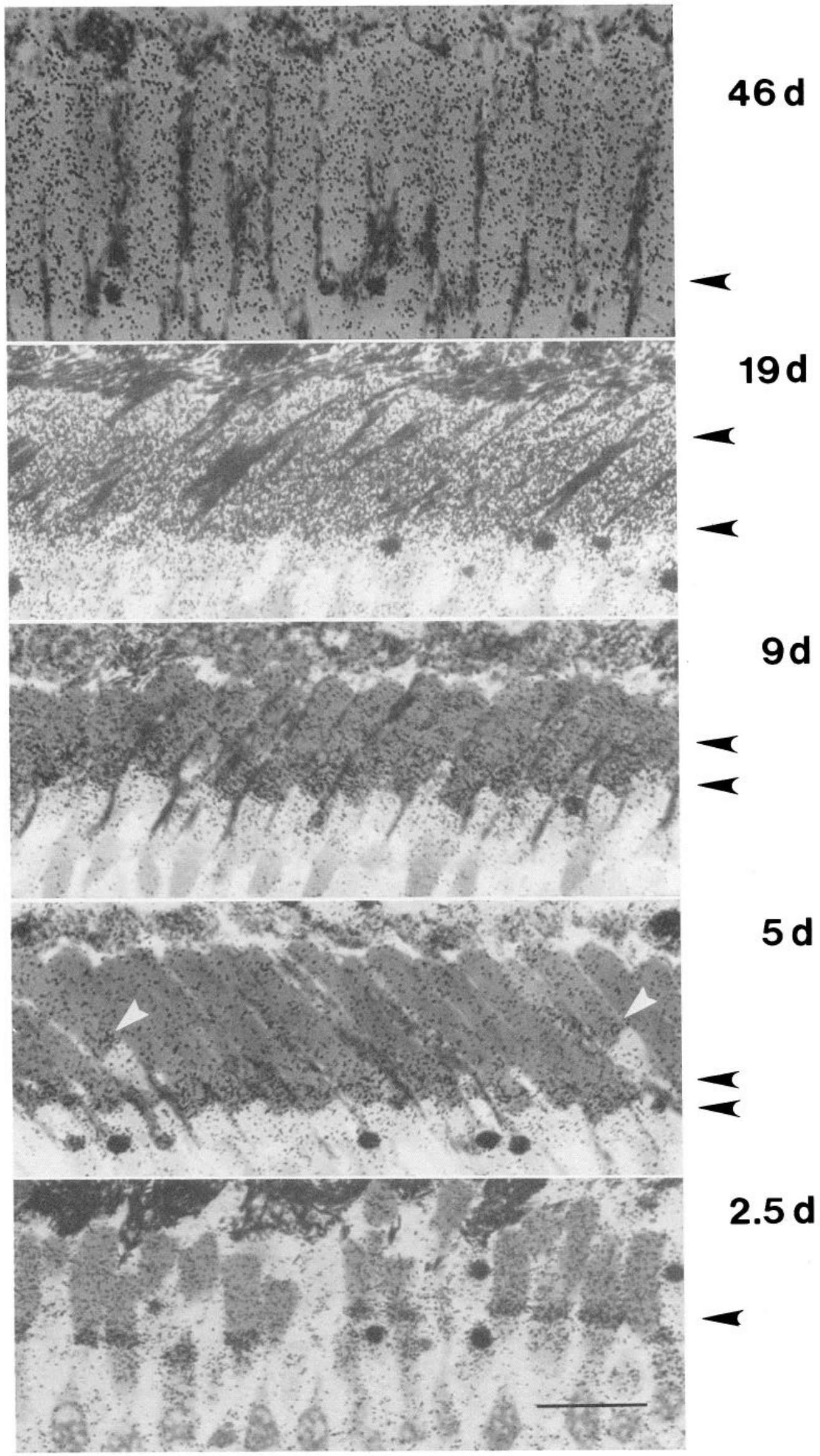

Figure 5. Labeling pattern as a function of time after injecting ${ }^{3} \mathrm{H}-22: 6$. Times from dorsal lymph sac injection to sampling are noted in days at the right. Notice that the ROS label diffusely. In addition, a dense region forms at the base of the ROS. This region thickens continually until it reaches the overlying pigment epithelium. The distance from the base of the outer segment to the front of this dense region is indicated for each time point by a pair of arrows at the right. By day 46, the front of the dense region has moved past the receptor tips. The white arrows indicate green ROS. Scale bar, $20 \mu \mathrm{m}$. 

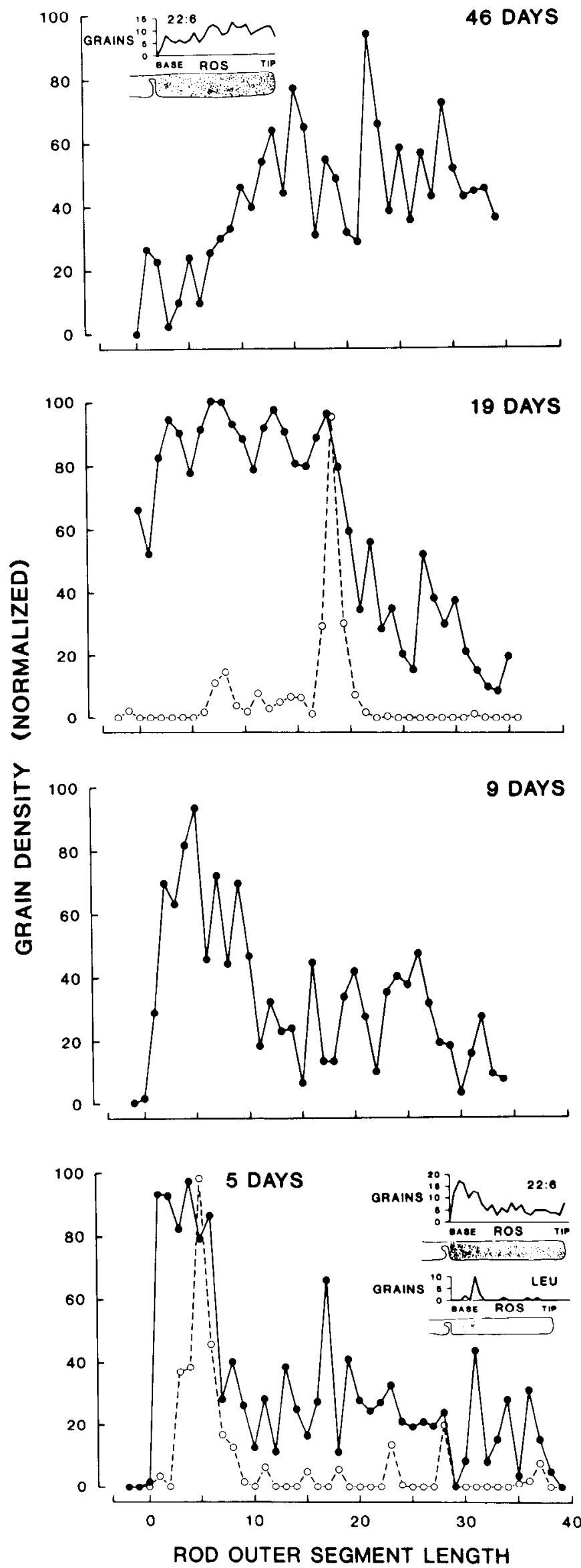

autoradiographic profile of the right eye. Another assumption used in the calculations is that the diffuse label is uniform in the ROS and that there is a constant and identical rate of disc synthesis throughout the retina. While the potential error is significant, Table 1 shows increasing label of the dense basal clusters and the inner segments from 2.5 to $19 \mathrm{~d}$, with a reduction of the ROS diffuse label.

\section{HPLC analysis of 22:6 in the retina and liver}

Throughout the labcling period, more than $95 \%$ of the retinal label was 22:6. Even though densely labeled photomembranes began appearing in phagosomes of the pigment epithelium after $30 \mathrm{~d}$ as a result of daily photomembrane turnover (Fig. 8), 46 $\mathrm{d}$ samples contained ${ }^{3} \mathrm{H}-22: 6$ exclusively. Only when the $67 \mathrm{~d}$ retinas were examined did other labeled fatty acids appear (Fig. 9). These included small amounts of $22: 5$ and $16: 0$, as well as 2 other unidentified fatty acids.

The only radioactivity detected in the liver through $46 \mathrm{~d}$ after injection was that of ${ }^{3} \mathrm{H}-22: 6$. In addition, less than $0.5 \%$ of the total retinal radioactivity was present in lipid-free tissue residues, indicating no significant labeling of protein.

\section{Discussion}

This study demonstrates that systemically injected ${ }^{3} \mathrm{H}-22: 6$ is avidly taken up from the choriocapillaris by rod photoreceptor cells in the frog. This fatty acid is used in the inner segments of the visual cells for the synthesis of docosahexaenoyl-phospholipids. It is shown here for the first time that the movement of some phospholipids correlates with that of newly synthesized rhodopsin during ROS renewal. No other lipid precursors have allowed the establishment of this correlation (see Bibb and Young, 1974a, b; Anderson et al., 1980a-c; Fliesler and Basinger, 1987). Moreover, ${ }^{3} \mathrm{H}$-labeled docosahexaenoyl-phospholipids do not move as a narrow band during rod outer segment renewal, as ${ }^{3}$ H-leucine does (Young, 1967; Hollyfield, 1979), nor do they form an initial dense basal region which soon diffuses into the ROS, as has been shown for glycerol (Bibb and Young, 1974b) and for vitamin A (Defoe and Bok, 1983). The labeling profile of 22:6 is unlike that obtained by using other phospholipid precursors (Bibb and Young, 1974a, b; Anderson et al., 1980ac; Mercurio and Holtzman, 1982; Matheke and Holtzman, 1984), resulting in 2 distinct regions along the ROS. Silver grains form

Figure 6. Quantitative assessment of the distribution of silver grains in ROS. Representative plots of digitized ROS autoradiograms of 3 cells each from single retinas at selected time points showing the amount of tritium label along the length of the ROS. The base of the ROS at the left is represented by zero, while the tip is positioned to the right, usually near 35. 22:6 is represented by filled circles and solid lines; leucine is shown with open circles and dashed lines. Leucine labels are illustrated for days 5 and 19. Each data point represents a window at which the density of silver grains per area has been measured. The density (vertical axis) has been arbitrarily set so that the maximum response equals approximately 100 . No attempt was made to correct for variations in ROS length since absolutc distance from ROS base is critical. Each ROS base is set at 0 (horizontal axis). As experimental time progresses, it can be seen clearly that the front of the dense 22:6 region coincides with the leucine marker (days 5 and 19). By day 46, the 22:6 label has begun to disperse basally, suggesting a depletion of the original dense region. The insets are similar plots made by hand-counting autoradiographic silver grains of single ROS against a grid overlay. The original tracing is shown below each plot. The vertical axis represents the number of silver grains. The lower inset represents 22:6 and leucine profiles after $7 \mathrm{~d}$; upper inset, a 22:6 profile after $46 \mathrm{~d}$. 


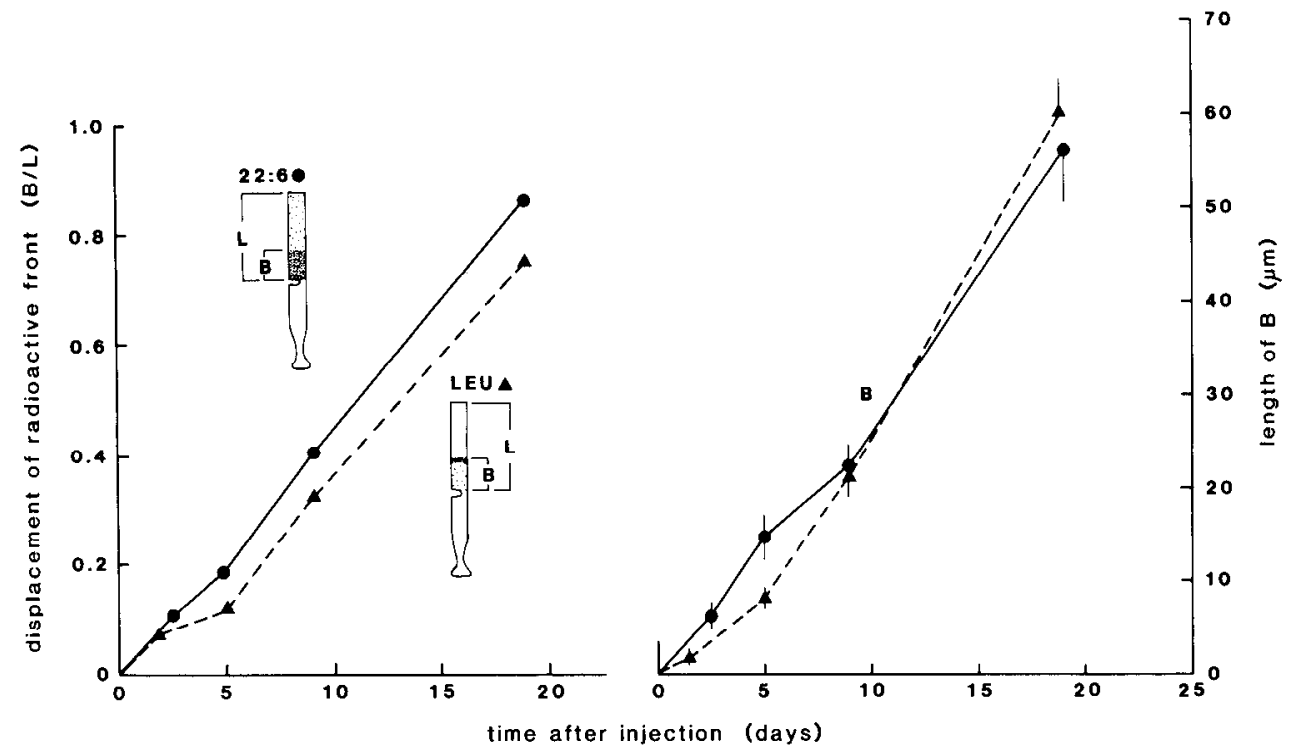

Figure 7. Migration rates of rhodopsin and 22:6-containing phospholipids during rod outer segment renewal. Leucine-labeled rhodopsin (triangles) is compared with 22:6-labeled phospholipids (circles). At the left, the ratio of band distance $(B)$ from base of ROS is compared to ROS length $(L)$ as a function of time. When $B=L$, the ratio is 1 , and the front will have reached the tip of the photoreceptor. To the right, absolute migration rates $(B)$ arc illustrated (ROS of the frog are $55-65 \mu \mathrm{m}$ long). Both graphs illustrate comigration of the 2 tritiated molecules, leucine (rhodopsin) and 22:6 (phospholipid). Standard deviations $(n=8-12)$ are represented for one eye at each time point. a dense region at the base of the ROS which grows toward the apical tip as a function of time after injection. The leading edge of this region corresponds in position to the front of the leucine band. A second, diffuse label over the entire ROS is seen throughout the $30 \mathrm{~d}$ interval, from the beginning of photoreceptor disc synthesis to eventual disc shedding. Phagosomes formed throughout this interval reflect the labeling pattern of the ROS, suggesting that at least some 22:6-containing phospholipids are cycled through the pigment epithelium before they are recycled to the visual cells.

Labeled 22:6 has been found to be mainly in phospholipids of ROS in experiments similar to those described here. ROS were purified from frogs 4-10 d after dorsal lymph sac injection of labeled fatty acids. ROS lipid classes were then separated by 2-dimensional thin-layer chromatography, revealing that over $90 \%$ of the labeled $22: 6$ was in phosphatidylcholine, phosphatidylethanolamine, and phosphatidylserine (N. G. Bazan et al., unpublished observations).

The 2 labeling patterns of 22:6 in ROS may be explained by different fatty acid uptake routes in the rod photoreceptor cell as depicted in Figure 10. In both instances, blood-borne ${ }^{3} \mathrm{H}-22: 6$ is taken up at the level of the choriocapillaris and, by way of the retinal pigment epithelium, arrives at the interphotoreceptor matrix. Tritiated 22:6 is differentially taken up by retinal cells according to the delivery route of the fatty acid. When introduced through the systemic circulation (i.e., intravenous or dorsal lymph sac injections), 22:6 preferentially labels photoreceptor cells, while fatty acid delivered through the vitreous or to eyecups in vitro almost exclusively labels cells of the neural retina. Normal supply of 22:6 to the retina of amphibians is made through the choriocapillaris since they lack retinal microvasculature in the inner plexiform layer. The same pathway may be used in mammals since the present observation agrees with biochemical data showing that during development and differentiation of the mouse retina, 22:6 is supplied through the bloodstream from the liver, possibly esterified in phospholipids of certain lipoproteins (Scott and Bazan, 1989).

In the inner segments of rod photoreceptors, 22:6 is used for the synthesis of phospholipids, which may in turn become integrated into new membrane at the endoplasmic reticulum and
Golgi apparatus while opsin is being added. A low- $K_{m}$ docosahexaenoyl-coenzyme A synthetase activity has been found in retinal microsomes (Reddy and Bazan, 1984, 1985). The action of this enzyme is followed by that of acetyltransferases that esterify 22:6 to phospholipids. In fact, retinal microsomes display an acetyltransferase activity that esterifies 22:6 to monoacyl-sn-glycero-3-phosphate (lysophosphatidic acid), resulting in the synthesis of 1-acyl-2-docosahexaenoyl-sn-glycero-3-phosphate, phosphatidic acid (Bazan et al., 1984). Subsequently, this phospholipid leads to the synthesis of 22:6-containing phosphatidylcholine in a reaction dependent upon the addition of CDP-choline and cytosolic supernatant to retinal microsomes (Bazan et al., 1984). A retinal subcellular fraction enriched in inner segments from photoreceptor cells seems to contain relatively high proportions of these pathways (Bazan et al., 1986). Moreover, the endogenous fatty acyl chains of phosphatidic acid from ROS (in frogs, rats, and cattle) contain relatively large proportions of 22:6 and display active turnover, implying that 22:6 of ROS phospholipids is metabolically highly active (Bazan et al., 1982). Figure 10 depicts 2 molecular species of docosahexaenoyl-phospholipids among several being synthesized; one may represent the predominant molecular species of phospholipid in the growing, dense-label region reported here (Fig. 10). This dense basal label may result from accumulation of a newly synthesized molecular species of phospholipid subsequently inserted into nascent photomembrane. The leading edge of this

Table 1. Autoradiographic analysis of 22:6 distribution in frog retinas

\begin{tabular}{lll} 
& Percent label \\
\cline { 2 - 3 } Tissue layer & $2.5 \mathrm{~d}$ postinjection & $19 \mathrm{~d}$ postinjection \\
\hline Retina (minus PE) & 100 & 100 \\
ROS diffuse label & 8 & 6 \\
ROS dense label & 4 & 16 \\
Inner segments & 17 & 20 \\
Neural retina & 71 & 57 \\
$\mu$ Ci/eye & 2.56 & 1.84 \\
\hline
\end{tabular}


Figure 8. Light micrographs depicting grain distribution throughout the ROS and pigment epithelium during shedding and phagosome formation. Description of the triggering of shedding and phagocytosis is in Materials and Methods. A, Retina induced to shed 5 $\mathrm{d}$ after injection of ${ }^{3} \mathrm{H}-22: 6$. A thin region at the base of the ROS shows the dense silver grain region, while the rest of the ROS has labeled diffusely. Phagosomes (arrows) within the pigment epithelium contain diffuse label. The large, spherical structures in the pigment epithelium are heavily labeled oil droplets. $B$, Retina induced to shed 28 $\mathrm{d}$ after injection of ${ }^{3} \mathrm{H}-22: 6$. Discs that were formed when tritium was introduced into the animal are now being shed (see Fig. 7). By $28 \mathrm{~d}$, ROS have become completely filled with the dense form of the label; the newly shed phagosomes (arrows) also contain this label. $C$, Retina that was not induced to shed at day 28 . While ROS are heavily labeled with ${ }^{3} \mathrm{H}-22: 6$, no phagosomes appear in the very lightly labeled pigment epithelium. $D$, Unstained retinal autoradiogram at day 28 . All contrast is due to the presence of autoradiographic silver. Note that the oil droplets of both the pigment epithelium and the cones are heavily labeled. This labeling pattern with ${ }^{3} \mathrm{H}-22: 6$ occurs throughout these experiments; oil droplets initially label heavily, but then gradually diminish as a function of postinjection time. No such labeling pattern is seen with ${ }^{3} \mathrm{H}$-leucine (see $E$ ). $E$, Retina induced to shed $28 \mathrm{~d}$ after the injection of ${ }^{3} \mathrm{H}$-leucine. This demonstrates that at $28 \mathrm{~d}$, the initially labeled discs have just reached the pigment epithelium and are being shed. The newly formed phagosomes (arrows) contain a band of ${ }^{3} \mathrm{H}$-leucine labeled rhodopsin. Scale bar, $20 \mu \mathrm{m}$.
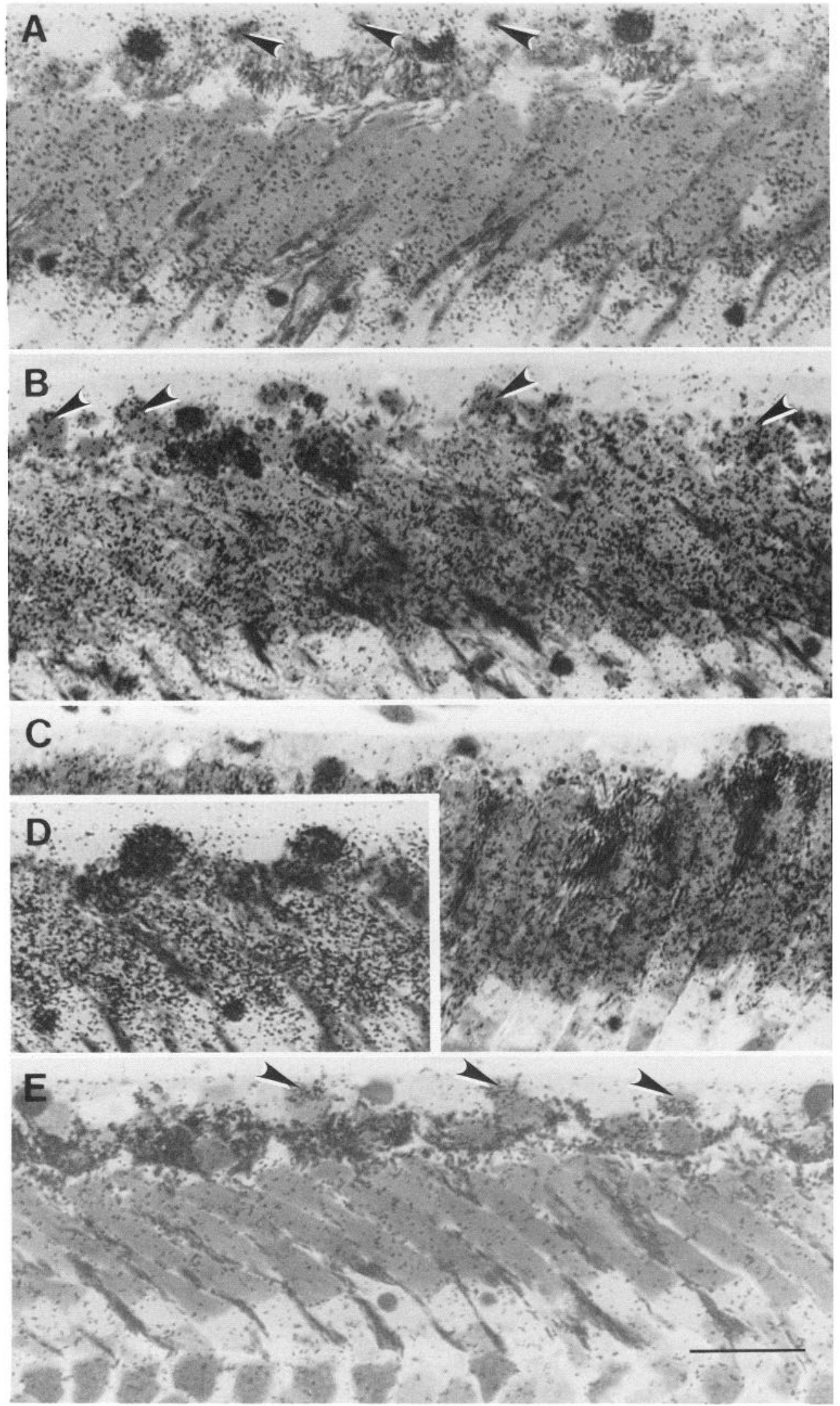


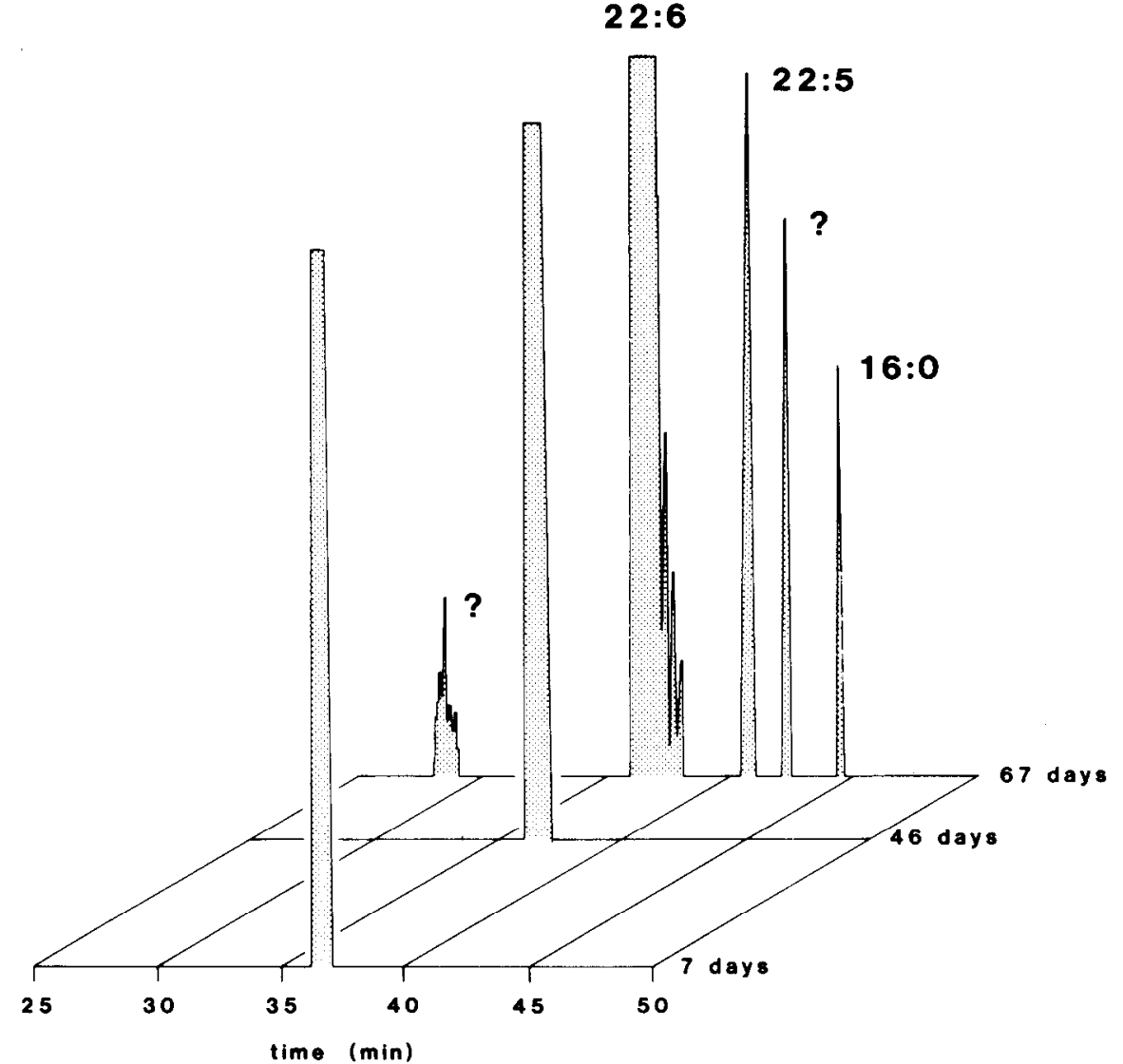

Figure 9. HPLC analysis of fatty acid methyl esters from retinas sampled at 7,46 , and $67 \mathrm{~d}$ after injection of ${ }^{3} \mathrm{H}$ 22:6 into the dorsal lymph sac. Docosahexaenoic acid (22:6) is the only labeled fatty acid through day 46 . Our analysis conditions (lipid extraction, methanolysis, partition, on-line HPLC radioactive detector) provide for recovery of $85-90 \%$ of labeled fatty acids. Some conversion begins to occur by day 67 , but only small amounts of other fatty acids demonstrate tritium labeling. HPLC retention time is denoted in minutes along the horizontal axis. dense label coincides with the leucine band, reaching the pigment epithelium in about $30 \mathrm{~d}$. This implies that some 22:6containing phospholipids move with the newly synthesized rhodopsin. Additionally, this dense region thickens from the base toward the apex, as if it were constantly being synthesized or added to, maintaining a steady progress toward the pigment epithelium at the same rate as a labeled protein band. HPLC analysis of the retina confirms that most of the label is $22: 6$, even $45 \mathrm{~d}$ after systemic injection. Docosahexaenoic acid-containing phospholipids comprise a significant portion of the rhodopsin microenvironment (Dratz and Deese, 1986). We suggest that the 22:6-enriched phospholipids of the dense label at the base of the outer segment are physically associated with rhodopsin of the newly synthesized membrane and remain so until reaching the apex of the photoreceptor. There is no direct evidence for an association between a molecular species of phospholipid-containing 22:6 with rhodopsin. However, the coinciding, moving fronts of the ${ }^{3} \mathrm{H}$-leucine band and the ${ }^{3} \mathrm{H}-22: 6$ dense label suggest this possibility. Recent data show that certain molecular species of phosphatidylcholine-containing 22:6 are not extracted from ROS by the usual procedures and require hexane extraction due to a tight interaction with rhodopsin (Aveldano, 1988, see below). These studies have been conducted in isolated ROS and the 22:6-containing molecular species of phosphatidylcholine have been characterized by gas chromatography-mass spectrometry (Aveldano and Sprecher, 1987; Aveldano, 1988). To date, no direct biochemical studics of the 22:6-containing phospholipids of the base of the ROS have been conducted. The slight decrease in silver grain density near the
ROS base by day 46 suggests, by extrapolation, that dilution with nonradioactive $22: 6$ has begun by about day 60 . According to our hypothesis, greater or lesser amounts of initial label $\left({ }^{3} \mathrm{H}-\right.$ 22:6) would affect only the intensity of the dense label, not the rate at which it decreases. Therefore, if final dissipation of the densely labeled region can be extrapolated to about $60 \mathrm{~d}$, then the molecular species of 22:6-containing phospholipids (associated with rhodopsin) must turn over roughly every outer segment cycle (i.e., $30 \mathrm{~d}$ ).

Since the overall, diffuse labeling pattern (filled triangles in Fig. 10) accumulates rapidly, it likely involves lipid cxchangc in the ROS, perhaps by a phospholipid exchange protein (Dudley and Anderson, 1978). Figure 10 depicts 2 possible mechanisms to explain the diffuse silver grains in the ROS. In Figure $10 \mathrm{~A}$, a rapid exchange stemming from the dense-label region is shown, and in Figure $10 \mathrm{~B}$, the diffuse silver grains are shown arising from 22:6 arriving from the interphotoreceptor matrix and bypassing lipid synthesis mechanisms or membrane assembly at the inner segment. Interestingly, the monkey interphotoreceptor matrix contains endogenous 22:6 noncovalently bound to interphotoreceptor retinoid-binding protein, as well as to other proteins (Bazan et al., 1985). Available data cannot conclusively exclude either model A or B. Our results are consistent with a diversity of pathways for lipid routing in rod photoreceptor cells (Holtzman and Mercurio, 1980; Mercurio and Holtzman, 1982; Matheke and Holtzman, 1984; Fliesler and Basinger, 1987). However, it is not yet known if the molccular species of phospholipid resulting in the dense-label region is utilized in photoreceptor membrane biogenesis along the path- 


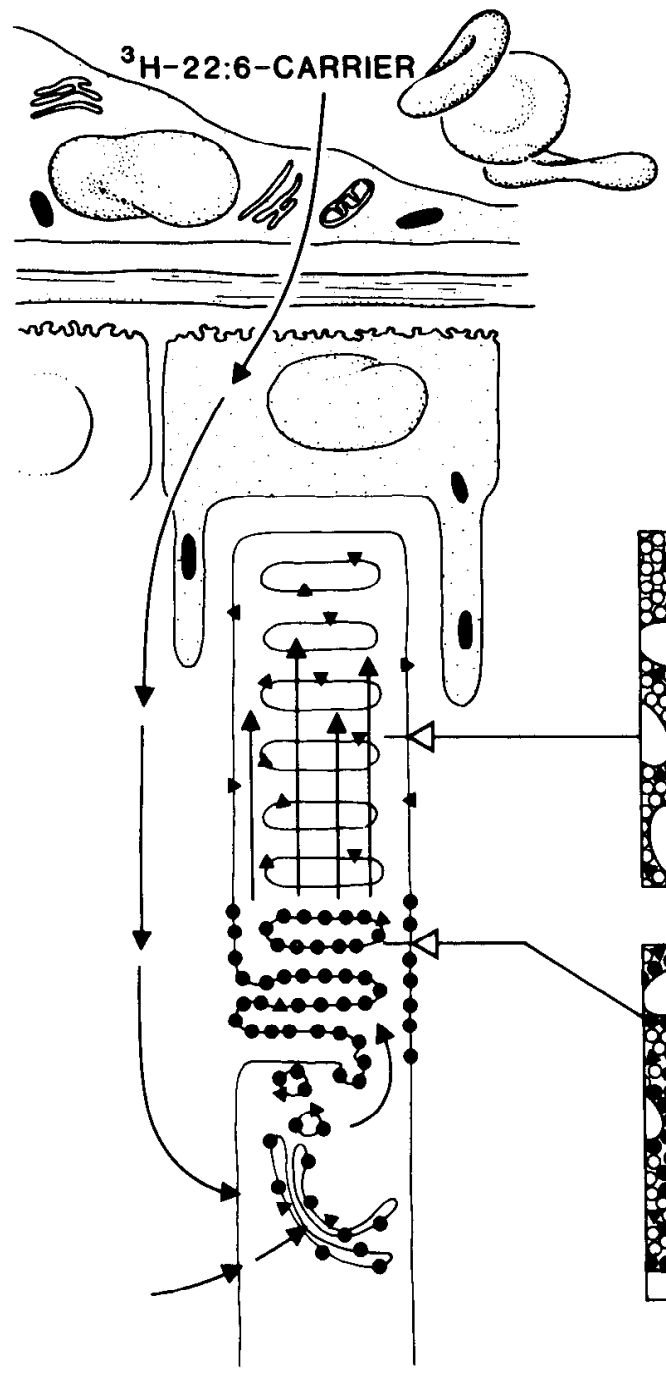

A

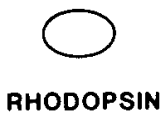

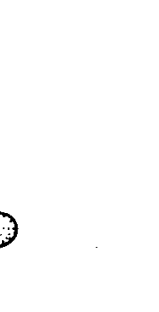

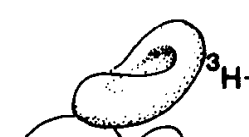

$3_{\mathrm{H}-28}$
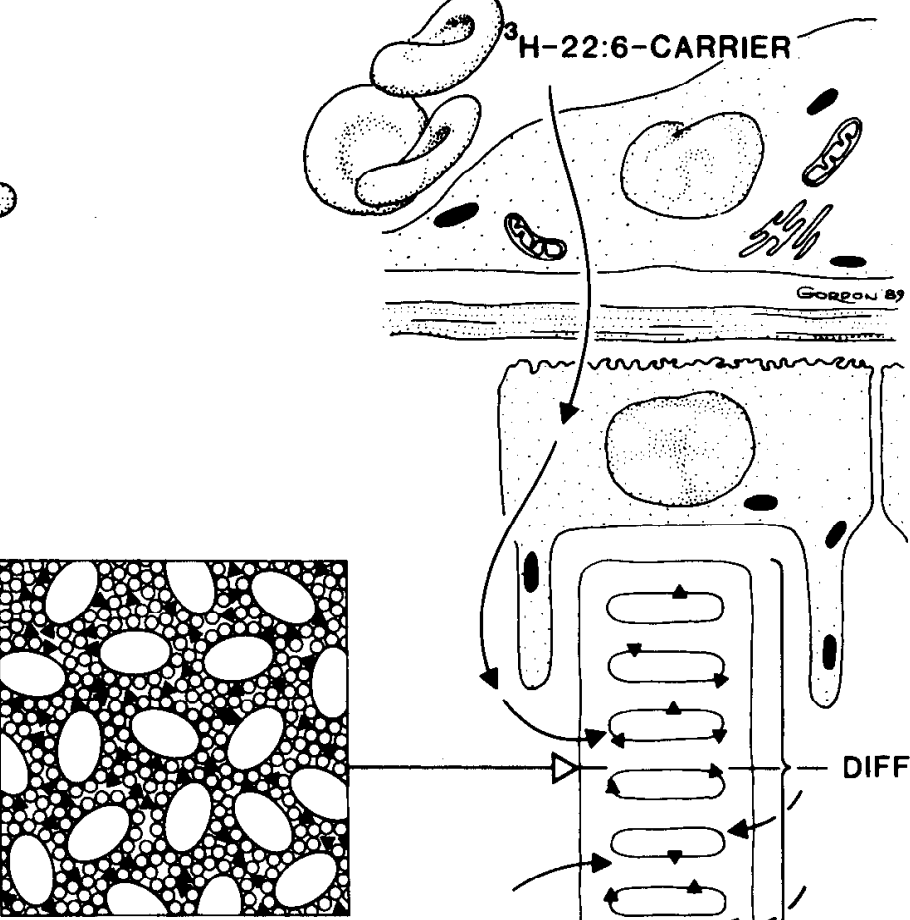

(1)
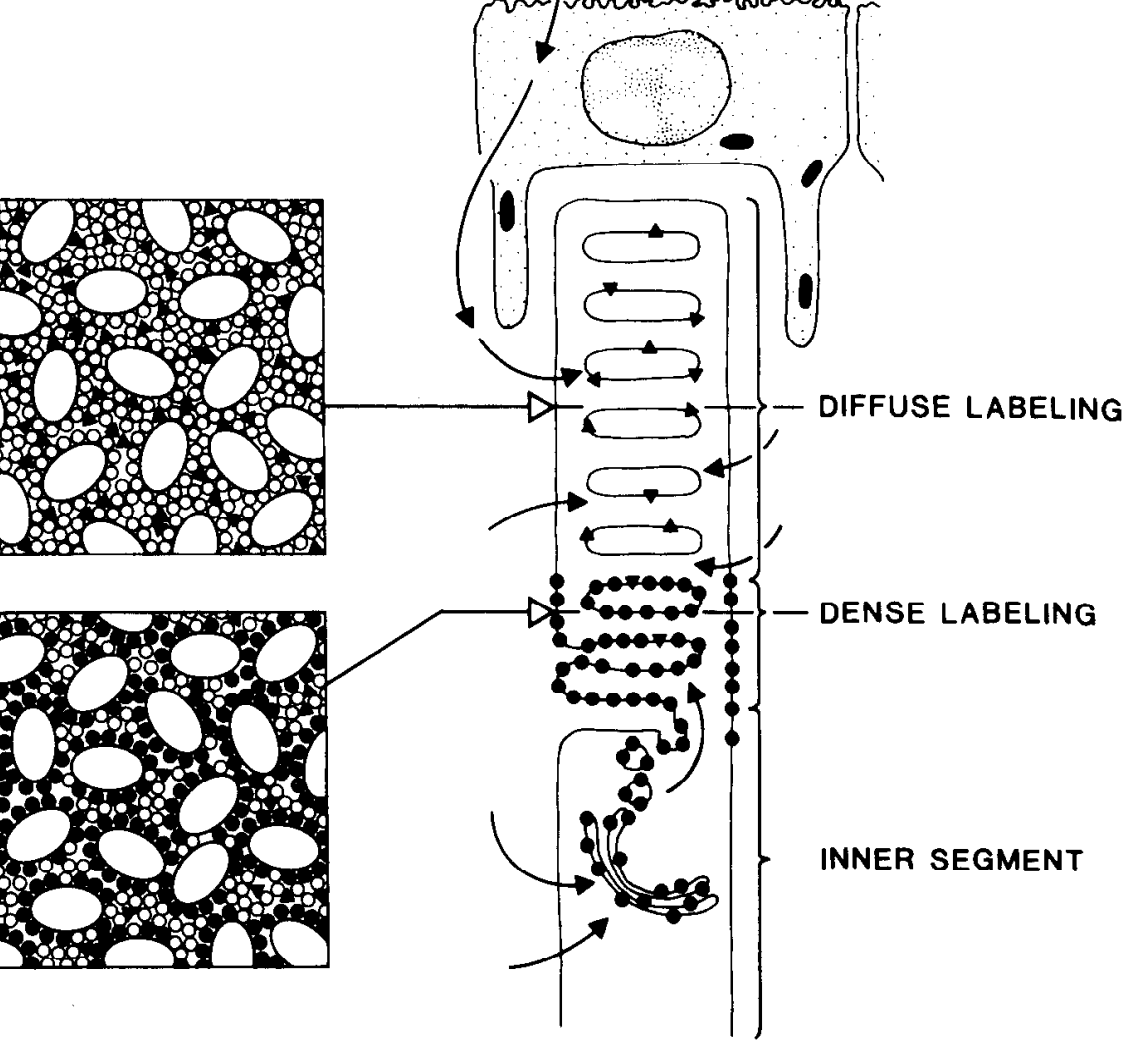

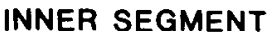

\section{O}

UNLABELED PHOSPHOLIPIDS

Figure 10. Schematic representation of the supply of 22:6 and labeling patterns in rod photoreceptor cells 1 week after ${ }^{3} \mathrm{H}-22: 6$ injection. The drawing of the photoreceptor cell depicts a stack of discs within the ROS. The squares are "top" views of disc membrane from the areas indicated by the open arrows. The ellipses represent rhodopsin, while the circles and triangles denote phospholipids of the membrane bilayer. Filled circles represent ${ }^{3} \mathrm{H}-22: 6$-containing phospholipids, noncovalently associated with rhodopsin. Disc membranes of apical regions of the photoreceptor contain sparingly labeled phospholipids (black triangles) that are apparently not associated with membrane proteins, arriving either by rapid exchange from the dense grain region $(A)$ or from the extracellular matrix $(B)$. The lowest arrow in both $A$ and $B$ indicates a possible supply of 22 : 6 lipids from the adjacent Müller cells (see Fig. 3).

way followed by opsin through the Golgi apparatus, specialized membrane vesicles, and discrete domains at the inner segment plasma membrane adjacent to the connecting cilium (Papermaster and Schneider, 1982; Besharse, 1986). Furthermore, our results showing that the leading front of the dense-label region of ${ }^{3} \mathrm{H}-22: 6$ coincides with that of the ${ }^{3} \mathrm{H}$-leucine band are the first to indicate a close association of a phospholipid with rhodopsin. This is unlike available evidence that suggests that phospholipids of photoreceptor cells are transported toward membrane biogenesis sites and undergo turnover independent of opsin (Hall et al., 1969; Bibb and Young, 1974a, b; Anderson et al., 1980a-c; Fliesler and Basinger, 1987). The ${ }^{3} \mathrm{H}-22: 6$ may label specific molecular species of phospholipids.
The retina (Aveldano de Caldironi and Bazan, 1977, 1980; Aveldano et al., 1983) and ROS (Miljanich et al., 1979; Aveldano and Bazan, 1983; Louie et al., 1988) contain unique molecular species of supraenoic phospholipids with 22:6 esterified in both $\mathrm{C}_{1}$ and $\mathrm{C}_{2}$. The molecular species of phospholipid tightly associated with rhodopsin may be a phosphatidylcholine with 22:6 esterified at $\mathrm{C}_{2}$ of the glycerol backbone, and a very longchain polyunsaturated fatty acid with 6 double bonds derived from 22:6 at $C_{1}$. This unique molecular species of phosphatidylcholine is selectively associated with rhodopsin, as shown by differential hexane lipid extraction of ROS (Aveldano, 1988). The rapidly diffusible label may correspond to a phospholipid containing 22:6 at $\mathrm{C}_{2}$, and other fatty acids at $\mathrm{C}_{1}$, a molecular 
species not preferentially associated with rhodopsin (Aveldano, 1987, 1988; Aveldano and Sprecher, 1987). Our solubilized, lipid-free retinas demonstrate no radioactivity associated with protein. This is in agreement with O'Brien et al. (1987), who have shown that no 22:6 can be detected by gas chromatography-mass spectrometry in covalent association with rhodopsin.

In conclusion, the major fatty acyl chain of phospholipids in photoreceptor membranes, 22:6, does not behave like other lipids during visual cell renewal in the frog. A dense silver grain region at the base of the ROS expands toward the tip of the photoreceptor outer segment during renewal. The front of this region coincides with the front of the ${ }^{3} \mathrm{H}$-leucine band (a rhodopsin marker) that results when the radioactive amino acid is injected, suggesting an association between the 22:6-containing phospholipid and the protein. Furthermore, 2 molecular species of phospholipids (or 2 groups of molecular species), both containing docosahexaenoyl chains, may explain the labeling profile arising from ${ }^{3} \mathrm{H}-22: 6$. A unique molecular species of phospholipid tightly associated with rhodopsin may give rise to the densely labeled region. A second, rapidly labeled, diffuse pattern throughout the ROS may be due to a different molecular species (also containing 22:6) of phospholipids. Phagosomes containing ${ }^{3} \mathrm{H}-22: 6$-phospholipids are formed throughout the disc membrane turnover cyclc, suggesting that both the diffuse and the dense form of label leave the ROS and then cycle through the pigment epithelium before being reutilized. Oil droplets in the pigment epithelium and the cone cells label rapidly, suggesting that some 22:6 is temporarily stored in neutral lipids. This is supported by work showing the rapid accumulation of another polyunsaturated fatty acid, arachidonic acid, in triacylglycerols in the in vitro bovine retina (Bazan and Bazan, 1975). Since label gradually diminishes over long periods of time, those droplets may serve to gradually resupply $22: 6$ to the photoreceptors or other cells of the retina. Finally, the supply of 22:6 to the rod photoreceptor cells is made from the choriocapillaris.

\section{References}

Anderson RE, Kelleher PA, Maude MB (1980a) Metabolism of phosphatidylethanolamine in the frog retina. Biochim Biophys Acta 620: 227-235

Anderson RE, Kelleher PA, Maude MB, Maida TM (1980b) Synthesis and turnover of lipid and protein components of frog retinal rod outer segments. Neurochem Int 1:29-42.

Anderson RE, Maude MB, Kelleher PA, Maida TM, Basinger SF (1980c) Metabolism of phosphatidylcholine in the frog retina. Biochim Biophys Acta 620:212-226.

Aveldano MI (1987) A novel group of very long chain polyenoic fatty acids in dipolyunsaturated phosphatidylcholines from vertebrate retina. J Biol Chem 262:1172-1179.

Aveldano MI (1988) Phospholipid species containing long and very long polyenoic fatty acids remain with rhodopsin after hexane extraction of photoreceptor membranes. Biochemistry 27:1229-1239.

Aveldano MI, Bazan NG (1983) Molecular species of phosphatidylcholine, -ethanolamine, -serine, and -inositol in microsomal and photoreceptor membranes of bovine retina. J Lipid Res 24:620-627.

Aveldano MI, Sprecher $H$ (1987) Very long chain $\left(C_{24}\right.$ to $\left.C_{36}\right)$ polyenoic fatty acids of the n-3 and n-6 series in dipolyunsaturated phosphatidylcholines from bovine retina. J Biol Chem 262:1180-1186.

Aveldano MI, Pasquare de Garcia SJ, Bazan NG (1983) Biosynthesis of molecular species of inositol, choline, serine, and ethanolamine glycerophospholipids in the bovine retina. J Lipid Res 24:628-638.

Aveldano de Caldironi MI, Bazan NG (1977) Acyl groups, molecular species, and labeling by ${ }^{14} \mathrm{C}$-glycerol and ${ }^{3} \mathrm{II}$-arachidonic acid of vertebrate retina glycerolipids. Adv Exp Med Biol 83:397-404.

Aveldano de Caldironi MI, Bazan NG (1980) Composition and biosynthesis of molecular species of retina phosphoglycerides. Neurochem Int 1:381-392.
Bazan HEP, Bazan NG (1975) Incorporation of $\left({ }^{3} \mathrm{H}\right)$-arachidonic acid into cattle retina lipids: high uptake in triacylglycerols, diacylglycerols, phosphatidylcholine and phosphatidylinositol. Life Sci 17:1671-1678.

Bazan IIEP, Sprecher H, Bazan NG (1984) De novo biosynthesis of docosahexaenoyl phosphatidic acid in bovine retinal membranes. Biochim Biophys Acta 796:11-19.

Bazan HEP, Ridenour B, Birkle DL, Bazan NG (1986) Unique metabolic features of docosahexaenoate metabolism related to functional roles in brain and retina. Phospholipid Research and the Nervous System. Biochemical and Molecular Pharmacology. FIDIA Res. Ser. Vol 4 (Horrocks L, Freysz L, Toffano G, eds), pp 67-78. Padua: Liviana Press.

Bazan NG, Reddy TS (1985) Retina. In: Handbook of neurochemistry, Vol 8 (Lajtha A, ed), pp 507-575. New York: Plenum.

Bazan NG, di Fazio de Escalante MS, Careaga MM, Bazan HEP, Giusto NM (1982) High content of 22:6 (docosahexaenoate) and active [2$\left.{ }^{3} \mathrm{H}\right]$ glycerol metabolism of phosphatidic acid from photoreceptor membranes. Biochim Biophys Acta 712:702-706.

Bazan NG, Reddy TS, Redmond TM, Wiggert B, Chader GJ (1985) Endogenous fatty acids are covalently and noncovalently bound to interphotoreceptor retinoid-binding protein in the monkey retina. J Biol Chem 260:13677-13680.

Besharse JC (1986) Photosensitive membrane turnover: differentiated membrane domains and cell-cell interaction. In: The retina (Adler R, Farber D, eds), pp 297-351. Orlando, FL: Academic.

Bibb C, Young RW (1974a) Renewal of fatty acids in the membranes of the visual cell outer segments. J Cell Biol 61:327-343.

Bibb C, Young RW (1974b) Renewal of glycerol in the visual cells and pigment epithelium of the frog retina. J Cell Biol 62:378-389.

Bok D (1985) Retinal photoreceptor-pigment epithelium interactions. Invest Ophthalmol Vis Sci 26:1659-1694.

Defoe DM, Bok D (1983) Rhodopsin chromophore exchanges among opsin molecules in the dark. Invest Ophthalmol Vis Sci 24:12111226.

Dratz EA, Deese AJ (1986) The role of docosahexaenoic acid (22:6 omega-3) in biological membranes: examples from photoreceptors and model membrane bilayers. In: Health effects of polyunsaturated fatty acids in seafood (Simopoulos AP, Kifer R, Martin RE, eds), pp 319-351. New York: Academic.

Dudley PA, Anderson RE (1978) Phospholipid transfer protein from bovine retina with high activity towards retinal rod disc membranes. FEBS Lett 95:57-60.

Fliesler SJ, Anderson RE (1983) Chemistry and metabolism of lipids in the vertebrate retina. Prog Lipid Res 22:79-131.

Fliesler SJ, Basinger SF (1987) Monensin stimulates glycerolipid incorporation into rod outer segment membrantes. J Biol Chem 262: 17516-17523.

Gordon WC, Bazan NG (1989) Docosahexaenoic acid in rod outer segment renewal (abstr). Invest Ophthalmol Vis Sci (Suppl) 30:294.

Gordon WC, Keith ME (1987) Tubocurarine chloride inhibits rod outer segment shedding in the frog retina. Invest Ophthalmol Vis Sci 28:1030-1032.

Hall MO, Bok D, Bacharach ADE (1969) Biosynthesis and assembly of the rod outer segment membrane system. Formation and fate of visual pigment in the frog retina. J Mol Biol 45:397-406.

Hollyfield JG (1979) Membrane addition to photoreceptor outer segments: progressive reduction in the stimulatory effect of light with increased temperature. Invest Ophthalmol Vis Sci 18:977-981.

Holtzman E, Mercurio AM (1980) Membrane circulation in neurons and photoreceptors: some unresolved issues. Int Rec Cytol 67:1-67.

Louie K, Wiegand RD, Anderson RE (1988) Docosahexaenoate-containing molecular species of glycerophospholipids from frog retinal rod outer segments show different rates of biosynthesis and turnover. Biochemistry 27:9014-9020.

Marcheselli VL, Scott BL, Reddy TS, Bazan NG (1988) Quantitative analysis of acyl group composition of brain phospholipids, neutral lipids, and free fatty acids. Neuromethods 7:83-110.

Matheke ML, Holtzman E (1984) The effects of monensin and of puromycin on transport of membrane components in the frog retinal photoreceptor. II. Electron microscopic autoradiography of proteins and glycerolipids. J Neurosci 4:1093-1103.

Mercurio AM, Holtzman E (1982) Ultrastructural localization of glycerolipid synthesis in rod cells of the isolated frog retina. $J$ Neurocytol $11: 295-322$.

Miljanich GP, Sklar LA, White DL, Dratz EA (1979) Disaturated 
dipolyunsaturated phospholipids in the bovine retina rod outer segment disc membrane. Biochim Biophys Acta 55:294-306.

Neuringer M, Connor WE (1986) N-3 fatty acids in the brain and retina: evidence for their essentiality. Nutrition Rev 44:285-294.

O'Brien PJ, St Jules R, Reddy TS, Bazan NG, Zatz M (1987) Acylation of disc membrane rhodopsin may be non-enzymatic. J Biol Chem 262:5210-5215.

Papermaster DS, Schneider BG (1982) Biosynthesis and morphogenesis of outer segment membranes in vertebrate photoreceptor cells. In: Cell biology of the eye (McDevit DS, ed), pp 477-531. New York: Academic.

Ramón y Cajal S (1973) The vertebrate retina. In: The vertebrate retina. Principles of structure and function (Rodieck RW, ed), pp 772-904. San Francisco: WH Freeman.
Reddy TS, Bazan NG (1984) Synthesis of arachidonoyl coenzyme A and docosahexaenoyl coenzyme A in retina. Curr Eye Res 3:12251232 .

Reddy TS, Bazan NG (1985) Synthesis of docosahexaenoyl-, arachidonoyl-, and palmitoyl-coenzyme $\mathrm{A}$ in ocular tissues. Exp Eye Res 41:87-95.

Scott BL, Bazan NG (1989) Membrane docosahexaenoate is supplied to the developing brain and retina by the liver. Proc Natl Acad Sci USA 86:2903-2907.

Young RW (1967) The renewal of photoreceptor cell outer segments. J Cell Biol 33:61-72. 